\title{
Planned Pharmacologic Target Mode of Action
}

National Cancer Institute

\section{Source}

National Cancer Institute. Planned Pharmacologic Target Mode of Action. NCI

Thesaurus. Code C147517.

A description of the cellular functional or anatomic change for the assumed target of the pharmacologic intervention. 